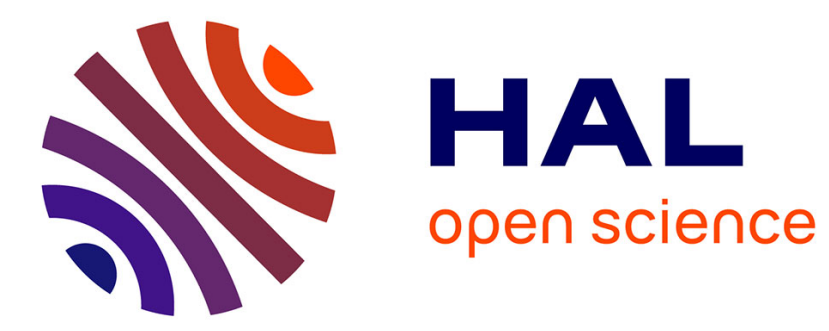

\title{
Digital Innovation and Social Dilemmas
}

\author{
Maria Åkesson, Michel Thomsen
}

\section{To cite this version:}

Maria Åkesson, Michel Thomsen. Digital Innovation and Social Dilemmas. Transfer and Diffusion of IT (TDIT), Jun 2014, Aalborg, Denmark. pp.49-61, 10.1007/978-3-662-43459-8_4 . hal-01381179

\section{HAL Id: hal-01381179 \\ https://inria.hal.science/hal-01381179}

Submitted on 14 Oct 2016

HAL is a multi-disciplinary open access archive for the deposit and dissemination of scientific research documents, whether they are published or not. The documents may come from teaching and research institutions in France or abroad, or from public or private research centers
L'archive ouverte pluridisciplinaire HAL, est destinée au dépôt et à la diffusion de documents scientifiques de niveau recherche, publiés ou non, émanant des établissements d'enseignement et de recherche français ou étrangers, des laboratoires publics ou privés. 


\title{
Digital Innovation and Social Dilemmas
}

\author{
Maria Åkesson and Michel Thomsen \\ Halmstad University \\ Sweden \\ maria.akesson@hh.se; michel.thomsen@hh.se
}

\begin{abstract}
Digital innovation is rapidly reshaping society, affecting fundamental aspects of our everyday activities and lives. This development is accompanied with benefits as well as social dilemmas. In this paper we approach this class of challenges in IS digital innovation research. We investigate how social challenges are attended in research agendas, and reflect upon social challenges emerging from a digital service innovation project. Based on the empirical case, we present a scenario that illustrates how social challenges can unfold in digital service innovation. The case exemplifies three conflicts of interest that are used to discuss implications for the research agendas for digital innovation. We propose that explicit attention is paid to social and ethical challenges, taking a large scale and interdisciplinary approach on social and ethical challenges in digital ecosystems.
\end{abstract}

Keywords: Digital innovation; research agendas; social and ethical challenges; social dilemmas

\section{Introduction}

Digital innovation is continuously reshaping everyday activities, affecting many aspects of our lives. Innovative digital services are designed and implemented in a variety of contexts, targeting new user groups and application areas. For example, digital services have been developed to promote independent living for elderly [1] and for medical support in homes for people with diabetes [2]. Innovative digital design is also implemented in numerous products. Newspapers and books are being digitized, cars have novel digital capability, shoes have embedded chips counting steps and measuring blood pressure, etc. The rapid development of digital technology enables innovative digital services, expanding design into new contexts, confronting us with new social dilemmas.

While digital innovation indeed enables novel values to large groups of people, others are left behind. As Walsham [3, p.91] pose, it is important to ask - Who benefits, and who is missed out? Walsham's question clearly has bearing on digital innovation and design. Within IS research more assessment 
of social consequences has been emphasisized [4]. Laying out a future agenda for the IS field, Walsham suggests use of critical approaches and strong ethical goals in IS research. Let us give an example of a social dilemma. Imagine a tourist bus equipped with an intelligent remote diagnostic system (RDS). The RDS predicts a break failure before entering downhill on Timmelsjoch-Hochalpenstrasse (Fig. 1), and a potential accident is luckily avoided.

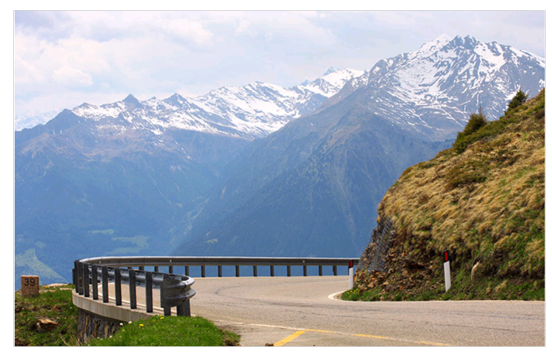

Fig. 1 Timmelsjoch-Hochalpenstrasse

This digital innovation clearly has benefits for safer bus transportation. Now, imagine the difference RDS can make in developing countries with limited resources, and where traffic accidents are common due to technical failures. So, how do we approach this class of challenges in digital innovation, affecting individuals, groups of people and society at large?

Since the millennium, digital innovation has been recognized as an important IS research theme. IS scholars like Kalle Lyytinen, Youngjin Yoo, Richard Boland and Ola Henfridsson have published proposals for research agendas, calls for research, and commentaries on digital innovation. In this paper we investigate how social challenges are treated in these publications, and reflect upon social dilemmas that emerged in a digital innovation project in the vehicle industry. In this project an intelligent RDS is developed with a vehicle manufacturer that seeks to expand business by adding digital services to their vehicles. There are technical and organizational challenges associated with this ambition, however in this paper we pay particular attention to the social challenges. We adopt a broad view on social challenges by referring to the world agenda for sustainable development, including aspects such as social responsibility, social justice and equity [5]. Using a scenario based on the RDS project, we illustrate potential benefits and social dilemmas in this project. A social dilemma emerges when actions or decisions impair, or has the potential to impair the wellbeing of an individual or group. Social dilemmas, or what Walsham [6] refers to as ethical issues, impact on the moral well-being of organizations and are important to IS scholars. The aim of this paper is to discuss and empirically illustrate social and ethical 
dilemmas accompanying digital innovation, and to contribute to the agenda for future research on digital innovation.

The paper is organized as follows. We start with an overview of challenges addressed in calls for research and research agendas on digital innovation. We then present the empirical context, the RDS project, and an empirically grounded scenario illustrating how social dilemmas can unfold in digital service innovation. Finally, we discuss social dilemmas and ethics in digital innovation research.

\section{Calls for Research and Research Agendas on Digital Innovation}

Digital innovation is a sub field in IS which captures the innovative capacity driven by the rapid development of digital technology. In general terms, innovation refers to an outcome perceived as new, weather it is an idea, object, or process, as well as to the process of creating this newness [7]. The newness may be a recombination of old ideas challenging the present order in such a way that it is new to the people involved [8]. Digital innovation refers combining digital and physical components in new ways making products programmable, addressable, sensible, communicatable, memorable, traceable and associable [9]. Such digitization distinguishes digital innovation from non-digital innovation. The generative capacity of digital technology enables refinement, expansion and recombination of digital services [10]. To its nature, digital innovation is distributed because the control over product components is distributed across multiple firms, and the product knowledge is distributed across heterogeneous disciplines and communities [10]. Accordingly, digital innovation spans beyond single stakeholders control [11], creating a paradox of change and control in digital innovation, see e.g. [12]. This in turn, continuously leads to new emergent and fragmented design situations [13].

By digital service innovation we refer to services enabled by digital innovation. To give an example we use the RDS. In this case, buses are digitized by embedding sensors, processors, wireless transmission and algorithms for prediction of faults in the buses. This digitization of buses provides a platform for digital services innovation. An example of a digital service enabled by the RDS is a real-time monitoring service of a fleet of buses offered to bus operating companies. This type of digital service innovation brings new business opportunities for manufacturing companies, expanding their business with digital services afforded by digital innovation [14].

Within the IS sub field of digital innovation a number of calls for research and research agendas on digital innovation have been published since the 
millennium. We have reviewed central research themes, and how social and ethical challenges are articulated in these publications (summarized in order of appearance in Table 1).

Table 1. Digital innovation research themes and challenges

Theme
$\begin{aligned} & \text { Information Systems Research - The Next Wave of Nomadic Computing, Vol. 13, No. 4, December 2002, pp. 377-388 } \\
& \text { Lyytinen K. and Yoo Y. - Research Commentary [15] }\end{aligned}$
\begin{tabular}{l|l} 
The authors analyse nomadic information environments \\
based on their prevalent features of mobility, digital \\
convergence, and mass scale, along, with their mutual \\
interdependencies.
\end{tabular}
$\begin{aligned} & \text { A research framework that organizes research topics in } \\
& \text { nomadic information environments at the individual, team, } \\
& \text { organizational, and interorganizational levels and is } \\
& \text { comprised of both service and infrastructure development, wi } \\
& \text { assess the opportunities and challenges for IS research (see } \\
& \text { Table 1 p. 381) }\end{aligned}$

\section{Attention to social and ethical challenges}

$\mathrm{Na}$ - The authors mention e.g. "At the level of services, IS researchers need to address the design, use, adaptation and impact of (digital) services." (see Table 1, theme 2, p. 381). Infrastructure for individual level - Governance and control address access privileges, privacy, and visibility of personal and public knowledge.

Communications of the ACM - Issues and challenges in Ubiquitous computing, 2002, Vol. 45, No.12, pp. 63-65. Lyytinen, K. and Yoo, Y. - Special issue article [16]

The authors suggest that radical improvements in microprocessor cost-performance ratios have, in 40 years, transformed the early large "computing machines" into compact devices that enable, mediate, support, and organize our daily activities.

The authors suggest that the shift toward ubiquitous
computing poses multiple novel, social, and organizational
challenges. Technical level issues of computer architecture
and configurations on a large scale. "... the emergence of
truly integrated sociotechnical systems will create a wide
array of research and policy issues that deal with social
organization, impact, and the future of work, organizations,
and institutions." (p. 65)
and institutions." (p. 65)

\section{Attention to social and ethical challenges}

The authors put forward questions that concern previously, unexplored (social) challenges that will emerge at the border between the technical and the social some issues are to be left outside the technical implementation to be addressed by social negotiation and due process; other issues should be addressed during technical design.

Organization Science - Organizing for Innovation in the Digitized World, Vol. 20, No. 1, January-February 2009, pp. 278279 Yoo, Y., Boland, R., Lyytinen, K. and Majchrzak, A. - Special issue [17]

The authors suggest that many challenges related to rapid and radical digitization will dominate the concerns of managers in this century. Studying the full impact of digital technology on innovation requires cross-disciplinary dialogue, richer vocabularies, diverse theoretical perspectives, new research methodologies, novel data analysis techniques and increase the breadth of research.

\section{Attention to social and ethical challenges}

$\mathrm{Na}$ - One question is: What are the social and material characteristics of digital technology that enable radical innovation?

Information Systems Research - The New Organizing Logic of Digital Innovation: An Agenda for Information Systems Research Vol. 21, No. 4, December 2010, pp. 724-735. Yoo, Y, Henfridsson, O and Lyytinen, K.-Research Commentary [10] \begin{tabular}{|l|l|} 
Pervasive digitization gives birth to a new type of product & A conceptual framework of a new IS research agenda with \\
\hline
\end{tabular} 
architecture: the layered modular architecture

A conceptual framework describing the new organizing logic

for digital innovation

\section{Attention social and ethical challenges}

$\mathrm{Na}$

Information Systems Research - Digital Infrastructures: The Missing IS Research Agenda

Vol. 21, No. 4, December 2010, pp. 748-759. Tilson, D., Lyytinen, K. and Sørensen, C. - Research Commentary [12]

Use of e.g. mobile services creates decentralized work organizations. Understanding these new dynamics will necessitate the field paying attention to digital infrastructures as a category of IT artefacts.

digital innovation including research themes relating to:

- New strategic frameworks

- Cooperate IT infrastructure

(a)

\section{Attention to social and ethical challenges}

$\mathrm{Na}$

MIS Quarterly - Computing in Everyday Life: A Call for Research On Experiential Computing

Vol. 34 No. 2, pp. 213-231, June 2010 Yoo, Y. - Issues and opinions [10]

As the rapid development of digital technology continues to make computers and computing a part of everyday experiences, we are once again in need of a new discipline of the artificial. The author argues that the IS community must expand its intellectual boundaries by embracing experiential computing as an emerging field of inquiry in order to fill this growing intellectual void.

Three research directions:

1) Theories of the nature of digital infrastructure as a separat type of IT artefact

2) Digital infrastructures as relational constructs are shaping all traditional IS research areas.

3) Paradoxes of change and control as salient IS phenomena. Suggestions on feasible methods for studying large scale sociotechnical phenomena.

\section{Attention to social and ethical challenges}

The author does not discuss topics like social challenges, ethics or "who is missed out?" in any detail. However he suggest research opportunities that relate to e.g. social challenges and integration of digital infrastructures with existing cultural infrastructures.

Information Systems Research - Report on the Research Workshop: "Digital Challenges in Innovation Research” 2010. Yoo, Y., Lyytinen, K., Boland, R. and Berente, N. - Research workshop to guide future research on digital innovations. [18] The authors suggest that ubiquity of digitalization is one of the primary forces behind innovations across a wide range of product and service categories.

An experiential computing design science research encompassing both behavioural and design sciences Six research opportunities are suggested to the IS research community relating to e.g. sociomateriality, generativity, group experience, and hybrid networks.

\section{Attention to social and ethical challenges}

$\mathbf{N a}$, One question deals with organizational, technological, social and economic implications of these issues, and what generative processes of innovation and change emerge from them.

Organization Science - Organizing for Innovation in the Digitized World. Vol. 23, No. 5, September-October 2012, pp. 1398-1408. Yoo, Y., Boland, R., Lyytinen, K. and Majchrzak, A. - Special issue [19]

Pervasive digital technologies change the nature of product and service innovations.

The organizational research implications of these three
Participants were asked to address four questions; one is What are the organizational, technological, social and economic implications of these issues, and what generative processes of innovation and change emerge from them? Six recommendations for future research: Multi disciplinary research, Design scholarship, Taking data seriously, Infrastructure, and Theorizing digital technology. 
digital innovation traits.

Attention to social and ethical challenges

$\mathbf{N a}$ - one article in the special issue deals with the consequences of digitalization of tools, in the context of car development. The authors (Bailey, Leonardi and Barley "explore how the increased dependence on more realistic digital tools to simulate, visualize, and test new complex products and their "crashability" leads to unintended consequences of separating physical objects and people from the virtual representations of design objects. They also show how the use of these highly realistic digital tools leads to recon-figurations of jobs and tasks and design outcomes are not always desirable. Finally, they point ou that placing too much trust on digital tools can backfire, and the likelihood of casting blind faith on digital technology increases as its power and capacity to represent the world grows. Their finding provides a contrarian perspective to existing stream of research.

MIS Quarterly - Digital Innovation as a Fundamental and Powerful Concept in the Information Systems Curriculum. Forthcoming 2014-2015. Fichman, R. G., Dos Santos, B. L. and Zheng, Z. E. - Issues and opinions [20]

Potential teaching themes related to IS core class. Examples: $\quad$ Suggestions to the IS research agenda for digital innovation: IT for competitive advantage, IT assimilation, digitally infused products, Ethical issues an IT, IT driven industry transformation, IT architecture, and interface design.
- Broaden innovation research

- Focus more attention on distinctiveness and heterogeneity - Focus more attention on how digital technology transforms innovation

Attention to social and ethical challenges

Ethical issues an IT is mentioned as a pedagogical theme, but not discussed

Table 1 shows that most themes relate to technical and organizational challenges, and that digital innovation is addressed as a large scale phenomenon. It also shows that central themes are the characteristics of digital technology, infrastructure and platforms, conditions for innovation and processes, and the general organizing logic of digital innovation. The table shows, however, that explicit attention is put to the nature of digital technology, while ethical considerations are articulated in only few of these publications.

\section{Empirical Context - the R2D2 Project}

To illustrate how social challenges can unfold in digital innovation research, we zoom into a collaborative research project in the vehicle industry. The R2D2-project started in April 2009 and was finalized in December 2013. The participants were a global vehicle manufacturer and a group of researchers in computer engineering and informatics.

The overall goal of the project was to develop an intelligent RDS that diagnose the health status of individual vehicles while in traffic. The RDS detects deviating patterns of vehicles with sensor technology in for example a fleet of city buses, and wirelessly transmit information about the buses while in traffic. This digital technology enables digital services such as prediction of 
faults, maintenance and traffic planning. In exploiting potential digital services enabled by the RDS, public bus transport organizations and bus operating companies were engaged in activities in the project as they are potential customers.

The incitement for the vehicle company to explore this innovation path is grounded in an ambition to expand their business with digital services coupled with their vehicles. The vehicle company has offered services to support the function of vehicles since 1985. This has been regarded as a post market and not a core business. In 2009, the company decided to prioritize servitization of their products, taking digital innovation initiatives such as the R2D2 project. This expansion brings technical, organizational and social challenges that were addressed in the project.

The rationale of an intelligent RDS, if successfully implemented and adopted, is benefits for traffic safety, reduced maintenance costs, increased life length of vehicles, increased up-time of operation, better work environment for bus drivers, improved service quality for public, etc. In other words, there are many potential benefits for large groups of bus riders, public transport companies, bus operators, and other stakeholders in the transport ecosystem. The project is therefore relevant in relation to the question - who benefits, and who is missed out.

The project was organized in two parallel parts. The first part involved the technical development of the RDS including diagnostics and prediction of maintenance, with a focus on methods for diagnosing and predicting faults. The second part involved digital service innovation enabled by the RDS. This included studying the RDS ecosystem, business potential and customer value of such services. While the first part started in 2009 and ended 2013, the second part started in 2010 and ended 2012. This paper is based on the second part where three informatics researchers and two service developers from the vehicle company participated. In this part of the project, the researchers interacted with different company representatives and external stakeholders. In Table 2 we present a summary of activities in the project.

Table 2. Summary of sources, activities and participants.

Duration

Number

Project meetings

\begin{tabular}{|c|c|c|}
\hline Monthly project meetings & $2-3$ hours & 20 \\
\hline Service development meetings with company service developers & $2-3$ hours & 30 \\
\hline \multicolumn{3}{|l|}{ Interviews } \\
\hline Vehicle company business managers & $1-2$ hours & 3 \\
\hline Vehicle company service development manager & 1 hour & 1 \\
\hline Vehicle company technology development manager & 1 hour & 1 \\
\hline Vehicle company repair and maintenance manager & 1 hour & 1 \\
\hline
\end{tabular}




\begin{tabular}{l|c|c}
\hline The vehicle company project manager & 2 hours & 1 \\
\hline Public transport organization traffic manager & 2 hours & 1 \\
\hline Bus operating company manager & 2 hours & 2 \\
\hline Workshops & 4 hours & 3 \\
\hline Workshops with vehicle production managers & 4 hours & 1 \\
\hline Future workshop with bus company representatives & 4 hours & 1 \\
\hline Scenario workshop with company representatives & 3 hours & 1 \\
\hline Group discussions & 2 hours & 2 \\
\hline Visit and group discussion at bus company site & \multicolumn{1}{|}{} \\
\hline Visits at bus company testing the RDS & --- & 54 \\
\hline & --- & 50 \\
\hline Documents & --- & 4 \\
\hline Minutes and notes of meetings &
\end{tabular}

In the monthly project meetings, participants from both project parts gathered to inform about and discuss project progress. These meetings were generic and cross disciplinary including technical as well as service innovation issues that emerged in the project. The meetings with service developers were planning meetings for the second part of the project and related to the digital service innovation. The interviews with the vehicle company representatives aimed at capturing the internal vision of RDS, and to get a deeper insight into the company reasoning on challenges associated with the digital services. The interviews with stakeholders outside the vehicle company aimed at exploring potential digital services based on the RDS. The workshops were explorative and aimed at creating scenarios for future digital services. In addition to meetings, interviews and workshops, there were group discussions in order to gain a holistic understanding of public bus transport. Finally, the data from these activities is complemented with documents such as minutes of meetings, project newsletters and project reports.

When interpreting and reflecting on the activities and interactions in the R2D2 project, we identified social dilemmas observed as conflicts of interest. We exemplify three of these conflicts in an empirically grounded scenario. The scenario is a means to bring life to the sociotechnical context and social dilemmas when RDS is implemented in a public transportation system.

\section{The Public Bus Transportation System in Cityville}

Alan is responsible for repairs and maintenance planning in BusOp, a bus operating company with the contract for public transport in Cityville. There are 65 vehicles of the brand SmartBus and 15 of the brand Riveras in the fleet of buses in Cityville. In high frequency traffic 78 of these buses are needed in 
operation, while in low frequency traffic there are about 50 buses in traffic. There are a two hours at nigh when the busses are out of operation. Alan's responsibility is to make sure that there are enough buses available at different times, and to reduce the risk of bus failure while in traffic. This is a complex task.

BusOp has a contract with the vehicle manufacturing company SmartBus for regular maintenance performed according to a schedule every 12 weeks on each individual bus. BusOp also has its own garage where they do checkups and some repairs work. At these occasions parts are, for preventive reasons, also exchanged even if they function. This is costly, but it is weighed against the risk of breakdowns while in traffic, which is a priority to avoid.

The high frequency timeslots are the bottlenecks in Alan's planning, but the biggest challenge is that individual buses do not have the same pattern. For some busses the 12 week regular maintenance is enough, but other buses might need it every 8 or even 6 weeks. There is even one bus that is seldom in traffic since the engine for some reason suddenly stops and the driver cannot start it again. Because of the individual differences Alan keeps journals on each individual bus.

Disturbance in operation happens every day. It can be anything from a door not closing, or flat tire, to break failure and electrical problems. In some cases the problem is easy to solve by a mechanic that drives to the bus and fixes the problem. In other cases a replacement bus needs to be put in, and the bus that has broken down is towed to the garage. These types of failures are disruptive and disturbing for the bus riders, and the situation is uncomfortable for the bus driver and other employees in BusOp. An even worse situation, that luckily happens less often, is when the break down causes an accident. The most common breakdown causing accidents is break failures.

SmartBus is an innovative company that in collaboration with researchers has developed a new intelligent RDS, enabling to predict faults such as break failure before they actually happen. The overall function of the RDS is to model and characterize operation for a fleet of buses, and to predict their maintenance need over a lifetime. The system is built on an architecture where sensors are embedded in different parts of the bus. The sensors generate on-board data that the system continuously mines. The information is sent to a back office server where it is analyzed for deviating patterns by comparison to reference data. This enables to detect faults early and to estimate the lifetime of parts (see Figure 2).

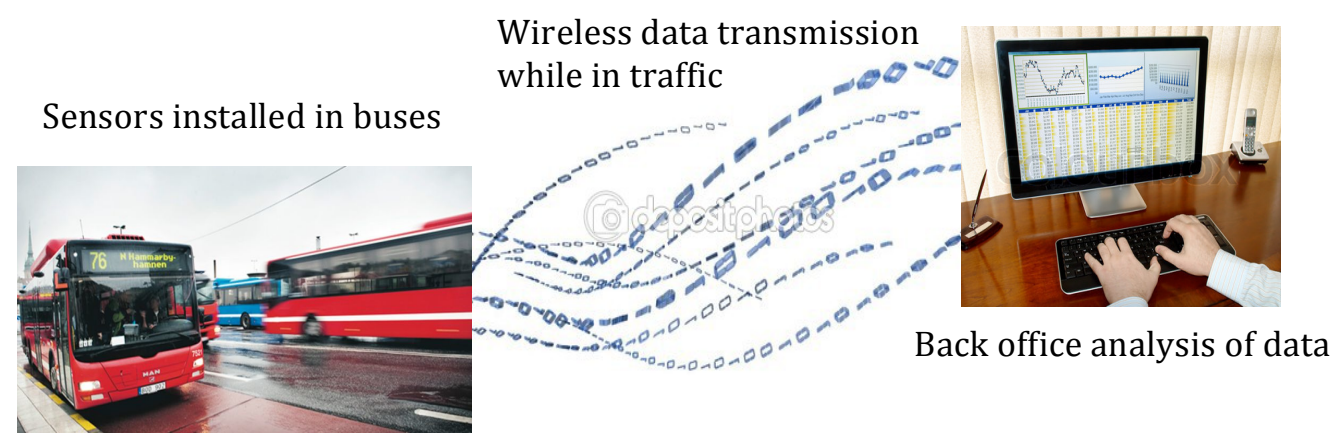


Figure 2. The overall principle of the RDS

SmartBus is now offering a set of digital services enabled by the RDS to BusOp. The service offer builds on a monthly payment for continuous monitoring of the health status of the buses. Alan thinks this service is a great help for his work. Now he can monitor the buses in real time while in traffic. He can better match maintenance with needs for individual buses. Alan can also prevent break-downs with help of the predictive information which in turn improve the overall up-time of the bus traffic. Most importantly, Alan really hopes this will make the zero accident goal of BusOp possible.

There is just on thing he is not so happy about. The RDS service is only available for the SmartBus vehicles, hence the Riveras buses cannot be connected to the service. Bob, the traffic planning manager, finds this challenging. He thinks it is difficult to decide what routes to put the now safer SmartBus buses and what routes to traffic with the Riveras buses. He has taken the Riveras out of school bus operation and now looks at statistics of traffic, passenger numbers etc. in order to make an as good a decision as he can.

Bob also works for the bus operating company BusGo in a neighbor city. BusGo drives only SmartBus vehicles equipped with RDS technology, but they have not found room for the RDS service in their budget. When Bob planes the school bus rout he cannot help thinking that the information in the system could prevent accidents. However, BusGo cannot does not get that information since they are not paying for the service. This makes Bob feel uncomfortable. He wonders what the parents would say if they knew this.

Alan really likes the RDS service. At a public transport convention Alan did a presentation together with Jessie from SmartBus. They explained the RDS and Alan spoke in very positive terms about it and how it contributes to better up-time for BusOp. Jessie explained how this is a new business opportunity and a how SmartBus now can have a more service oriented relation to BusOp. They can now work together to develop more digital services enabled by the RDS. At the convention a representative from the national transport administration asked about the type of data that the system mines. She asked if this perhaps is important information that can help develop new routines for roadworthiness, tests etc, in turn contributing to a safer traffic environment for all. "If your data shows that a part should be examined in roadworthiness tests it is of public interest that we have that 
information". Jessie hesitated, and realized that opening the system for public organizations would have implications for future business cases. She recognized that there is also a dilemma since the data mining enables analyzes of the weaknesses of SmartBus vehicles. This is of course of confidential nature for the SmartBus company.

\section{$5 \quad$ Discussion and conclusion}

In this paper we empirically illustrate social and ethical dilemmas accompanying digital innovation. We discuss that digital service opportunities bring social and ethical challenges. We show how this class of challenges is treated in IS research agendas for digital innovation, and we show how social dilemmas can emerge in digital innovation initiatives.

The review of calls for research and research agendas on digital innovation give at hand that the technical re-orientation in IS is well covered, while social challenges are articulated less explicit. Since digital innovation is diffused to new social contexts, it is reasonable to expect that a) potential teaching themes [20] more emphasis on social challenges and ethics, and b) social and ethical issues to be well mirrored in the research agendas.

The investigation into the digital innovation project showed how such challenges can unfold, in this case conflicts of interest. In summary, the scenario shows how third parties stakeholders such as bus riders might have different value perceptions and interests than what is inscribed in the service design. This was illustrated with the example of school buses and the bus operating companies' restrained budgets. Another conflict of interest was related to the challenge of balancing safety and risk in traffic planning, and the relation to business model interests of service provision. This is portrayed with the example of how the RDS was locked-in by the bus manufacturer for exclusively for their brand. Finally, the scenario gives an example of how public interest of data mining as a source for societal improvement, in this case improved traffic safety, potentially can be in conflict with the interests of companies building up data mines as a resource for digital service innovation.

Acknowledging the nature of digital innovation such as stakeholder heterogeneity, generativity, multi layered logic, distribution of knowledge, the paradox of change and control, see e.g. [9, 10, 11, 12], we suggest there are implications when addressing social challenges in digital innovation. As highlighted by the scenario, it is overpowering to one single actor to overview and control the chain of possible social consequences in large scale digital ecosystems. It is not always evident who is to take responsibility for, or to coordinate, the systematic application of moral principles in distributed innovation settings. Furthermore, the complex nature of digital innovation continuously creates new research and design situations. As a consequence 
new and multi disciplinary social challenges rapidly emerge in digital innovation settings. Without doubt, the fragmented nature of digital innovation adds to this complexity.

There certainly are important research themes addressing technical and organizational challenges in the research agendas for digital innovation. As illustrated in the scenario there is a complex maze of business opportunities and ethical challenges when digital innovation is diffused to new social contexts. The social dilemmas observes in the RDS project unmistakably point to social dilemmas that can emerge in digital service innovation when apprising value of services from different stakeholder's perspectives. The interest of one stakeholder can clearly lead to decisions that can impair the wellbeing of people. We propose that explicit attention is paid to social and ethical challenges, for example with collaborative analysis of consequences and models for shared ethical responsibility.

In the research agendas in reviewed, digital innovation is mainly addressed as a large scale phenomenon. Our understanding is that the structures and architectures on large scale have ethical implications that pervasively span everyday human activities. We therefore propose taking a large scale approach also to social and ethical challenges in digital ecosystems.

As suggested by e.g. Walsham [3] and Majchrzak et al. [4] this class of challenges cannot be solved by simple interventions - today's sociotechnical challenges encourage for multidisciplinary research initiatives. Consequently, we suggest that there is a need to find efficient ways to articulate and share our experiences and insights with researchers in relating disciplines to contribute to strong ethical goals in the future digital innovation research agenda.

\section{References}

1. Frantzidis, C. A., Bamidis, P. D.: Description and future trends of ICT solutions offered towards independent living: the case of LLM project. In Proc. of PETRA, 2009.

2. Kanstrup, A. M., Bertelsen, P., Glasemann, M., Boye, N.:Design for more: an ambient perspective on diabetes. In Proc. of PDC, 118-127, 2008.

3. Walsham, G.: Are we making a better world with ICTs? Reflections on a future agenda for the IS field, Journal of Information Technology, 27(2), pp. 87-93, (2012).

4. Majchrzak, M., Markus, L. M., Wareham, J.: ICT and Societal Challenges, Call for Papers Special Issue, MIS Quarterly, (2013). 
5. Report of the World Commission on Environment and Development: Our Common Future, Available at: http://www.un-documents.net/ocf02.htm\#I, Retrieved 20131121

6. Walsham, G.: Ethical theory, codes of ethics and IS practice, Information Systems Journal, Volume 6, Issue 1, p. 69-81, (1996).

7. Slappendel, C.: Perspectives on Innovation in Organizations. Organization Studies, vol. 17, no. 1, pp. 107-129, (1996).

8. Van de Ven, A. H.: Central Problems in the Management of Innovation. Management Science, vol. 32, no. 5, pp. 590-607, (1986).

9. Yoo, Y.: Computing in Everyday Life: A Call for Research On Experiential Computing, MIS Quarterly, Vol. 34 No. 2, pp. 213-231, (2010).

10. Yoo, Y., Henfridsson, O., Lyytinen K.: Research commentary - the new organizing logic of digital innovation: an agenda for information systems research. Information Systems Research, 21(4), pp. 724-735, (2010).

11. Henfridsson, O. Bygstad, B.: The Generative Mechanisms of Digital Infrastructure Evolution, MIS Quarterly 37, pp. 907-931 (2013).

12. Tilson, D., Lyytinen, K., Sørensen, C.: Research Commentary - Digital Infrastructures: The Missing IS Research Agenda. Information Systems Research, 21(4), pp. 748-759, (2010).

13. Thomsen, M., Åkesson, M.: Understanding ISD and Innovation through the Lens of Fragmentation, in Grand Successes and Failures in IT: Private and Public Sectors, Dwivedi, Y., Henriksen H.K., Wastell, D. and De R (Eds.), IFIP Advances in Information and Communication Technology, Springer (2013).

14. Akram, A., Bergquist, M., Åkesson, M.: Understanding Tensions in Incumbent Manufacturing Firms - A Study of Digitalized Product. HICSS'47, January 2014.

15. Lyytinen K., Yoo Y.: Research Commentary: The Next Wave of Nomadic Computing. Information Systems Research, Vol. 13, No. 4, pp. 377-388, (2002).

16. Lyytinen, K., Yoo, Y.: Issues and challenges in Ubiquitous computing. Communications of the ACM, 45 (12), 63-65, (2002).

17. Yoo, Y., Boland, R., Lyytinen, K., Majchrzak, A.: Organizing for Innovation in the Digitized World. Organization Science 20(1):278-279, (2009). 18.

18. Yoo, Y., Lyytinen, K., Boland, R., Berente, N.: The Next Wave of Digital Innovation: Opportunities and Challenges: A Report on the Research Workshop 'Digital Challenges in Innovation Research' (June 8, 2010). Available at SSRN: http://ssrn.com/abstract=1622170 or http://dx.doi.org/10.2139/ssrn.1622170, (2010).18]19. 
19. Yoo, Y., Boland, R., Lyytinen, K., Majchrzak, A.: Organizing for Innovation in the Digitized World. Organization Science 23(5):13981408, (2012).

20. Fichman, R. G., Dos Santos, B. L., Zheng, Z. E.: Digital Innovation as a Fundamental and Powerful Concept in the Information Systems Curriculum. MIS Quarterly, Forthcoming 2014-2015. 